one person, while on the other, there are seven. The tide is rising, and you only have time to row to one of the rocks and save those on it, before both rocks are engulfed by water, drowning those you are unable to save. The question is, whom do you save, the one or the many?

Many will take the answer to this question to be obvious: of course you should save the seven. What troubles the moral theorist is not whether the seven should be saved, but the difficulties in offering a cogent explanation of our strong intuitive belief that the right thing to do is to save the seven. Utilitarianism seems to provide the best theoretical account of our intuitions on this matter, but this is more of an anomaly than the norm. Theories that emphasize rights, on the other hand, are well known for avoiding questions about how the significance of numbers is to be explained, in those instances when we intuitively feel they do matter. And when rights theorists do address questions of this sort, they often come up with deeply counter-intuitive answers (like we have more reason to save the one than we do the seven).

There is a poverty of theoretical literature, that does not presuppose a utilitarian framework, on this topic despite this being a topic that is central to understanding issues concerning the distribution of scarce medical resources. Frances Kamm's magisterial and pioneering study of distribution problems in life and death situations is a seminal work in this area. There can be little doubt that Morality, Mortality will quickly become, in debates concerning the sorts of distribution problems that Kamm is concerned with, what Rawls's $A$ Theory of fustice is for more general debates about distributive justice. One may not agree with everything in it, but no one interested in the debate can afford not to read it, nor will anyone who reads it find him or herself other than greatly indebted to it.

The book is divided into three principal parts. The first discusses the question of what exactly the evil of death consists in. As Kamm's central questions concern questions of whom should be saved in life and death situations, a discussion of the type of value at stake in these scenarios could not be more appropriate. Too many philosophers discuss distribution questions independently of any concern for the character of the goods whose distribution is under discussion, believing, mistakenly in my view, that the character of the good being distributed makes no difference to what we say about how it should be distributed. Kamm, in her insightful and probing discussion of the disvalue of death, avoids this mistake.

The second section discusses various theoretical explanations as to why we might think that the right thing to do is to save the seven, not the one. This is by far the most technical section of the book, and the most difficult to read. Though the presentation of the arguments ranges between the daunting to, at times, the impenetrable, those who have an interest in how a non-consequentialist might tackle issues concerning the relevance of numbers for moral reasoning would do well to study this section of Kamm's book. Many of her ideas are highly original and exciting, though it is often difficult to see how they fit together as part of a continuous argument.

The third section of the book utilizes the theoretical resources already developed in the first two sections to discuss substantive issues in the distribution of medical resources, particularly questions of organ acquisition and fair-decision procedures for deciding between candidates for organ transplants.

Those whose principal concern is with health care ethics will no doubt find this part of the book the most rewarding. Though, once again, it is far from an easy read, it is rich in detail and insights. Kamm's style makes her arguments at times virtually impossible to follow, but one is nevertheless often struck by the thought that, though her general point is obscure, many of her specific points must certainly be correct, and constitute genuine insights that advance one's own thinking in these matters.

RAHUL KUMAR Balliol College, University of Oxford

\section{Fortress NHS: a philosophical review of the National Health Service}

David Seedhouse, Chichester, John Wiley and Sons, 1994, 178 pages, $£ 14.95$

As a useful aphorism, and one that leads us to the heart of David Seedhouse's stimulating book, we might take his remark (page 9) that while there are many accountants working in the health service 'there are no accountants of health care'. In his view there are none because the purposes of health care are not agreed, not least because the concept of health is itself disputed. Further, Seedhouse claims, even a general account of what we disvalue in illness (his own is in terms of loss of autonomy) will not determine particular decisions in health care (page 122). The message to those in the fortress is that in fact they cannot have determinate principles for solving their problems, but that they can do much better than their present conceptual chaos. The term 'fortress' represents Seedhouse's recognition that greater clarity can be a threat, given the changes that it might encourage.

Much of the book deals with the sources of the chaos. Seedhouse argues that the four principles generally held to provide the basis of the NHS have been given insufficient study and are, as usually understood, mutually incompatible. The first, that all health needs should be met, rightly leads him to an analysis of the concept of need. The analysis is somewhat hectic, with authors quoted and ideas raised, but too little guidance as to what is being carried forward and what discarded. The conclusion, though, that there are no universal needs, but that they are always relative to individual goals, has an important bearing on the question of expertise in the assessment of health care needs. On the second principle, concerning the standard of service, Seedhouse is initially reassuringly critical of current talk of 'quality' care, but unfortunately then seems to endorse this (and worse) usage by using it in his own discussion. It is a section that seems, philosophically, to take this rather vacuous language too seriously.

The discussion of the third principle, that of the right of equal access to NHS services, is rather more challenging. Seedhouse seems to accept the argument (which perhaps needs more exposition) that if health is a separable area of life, different in kind from other goods, and a matter of individual luck, then we should indeed have equal access to health care. He rejects it, though, by denying the premises, something that presumably threatens not just equal access but the whole idea of a public health service at all. (In fact his conclusion is that the principles, when clarified, do indeed suggest the abolition of the 
NHS in its current form.) Finally, the fourth principle, that of keeping costs as low as possible, provokes a savaging of the QALY (Quality Adjusted Life Year), with some related and telling points along the way. As he says, we should be wary of accepting the economists' simplifying assumptions when the problems are more than just academic exercises. He also shows that, as measures of disability and distress, QALYs are only arbitrarily restricted to illness.

The aim of the book is admirable and anyone seriously interested in the future of the NHS needs some familiarity with the issues that it covers. Whether they acquire it via this book, or try elsewhere, may well depend on their reaction to its rather busy presentation. Sub-headings, numberings, lists, italics, emboldening, italicised emboldening, indenting, dialogue, diagrams and boxes all rush to help us. Ungrateful readers may soon be longing for a stretch of quiet, open country, disturbed only by the warble of a distant chapter, or the rustle of a new paragraph.

HUGH UPTON

Centre for Philosophy and Health Care, University College of Swansea

\section{Genes and human self-knowledge}

Edited by Robert F Weir, Susan C Lawrence and Evan Fales, Iowa City, University of Iowa Press, 1994, 248 pages, $\$ 14.95$ sc, $\$ 29.95 \mathrm{hc}$

Advances in molecular biology have allowed the identification of genes involved in an escalating number of diseases. Not only have the genes for monogenic conditions such as Cystic Fibrosis, Huntington's disease and Muscular Dystrophy been identified, but also the genetic components of common diseases such as heart disease, cancer and diabetes mellitus are now being characterised. This rapidly changing state of genetic 'knowledge' has profound social, ethical, practical and health economic implications. Individuals can discover whether they are at risk of, or likely to develop, a disease at some point in their lives, many years before the onset of actual symptoms. This is likely to change how people are viewed by themselves and by others, such as, for example, insurance companies and employers.

One of the problems with this rapidly expanding state of scientific knowledge is that it may outstrip understanding of the impact of such testing on individuals. Scientists may have an insufficient knowledge or interest in ethics, philosophy or psychosocial issues, and vice versa, yet this is an area that clearly requires an interdisciplinary approach. Genes and Human Self Knowledge is the publication of the proceedings of a four-day symposium held at the University of Iowa in 1992, which attempts to provide this interdisciplinary approach. The symposium gathered together experts from several different areas; philosophers, historians, biomedical ethicists, molecular genetic scientists, clinical geneticists and members of the general public to address various aspects of human genetics with special reference to the impact of the Human Genome Project (HGP) on these aspects. The book is organised into three sections, containing the symposium papers in revised essay form. Each essay is followed by one or more shorter sections representing responses or comments by panellists.

Essays in the first section address 'Genetic identity and self-knowledge' and suggest that the HGP may affect views on equality, normality and personal responsibility for conduct. Another essay, by a psychologist, uses personal and very moving statements by people at risk of developing Huntington's disease. Section two addresses possible uses and misuses of genetic knowledge. This includes an essay on the different understandings and implications of the term eugenics, both now and historically. Other essays discuss the teaching of molecular biology in schools and colleges and the role of the media in shaping the public's opinions and understanding of genetics. Discrimination based on the results of genetic tests (diagnostic or prognostic) by employers and insurers is also covered. The last section considers the theme 'Genders, races and future generations' and discusses the basis for beliefs of racial and sexual differences as well as the importance of genetic variation.

Although this book describes many of the facts in relation to genetic information from an American point of view, the fundamental issues raised are universal. There is some repetition of issues between different essays, but they are all very readable and it is good to see essays on philosophical discussions intermingled with personal accounts of a genetic condition and with essays considering the biology of genetics. I would recommend this $\frac{2}{\infty}$ book to those interested in the special $\stackrel{\AA}{\complement}$ ethical issues surrounding genetic testing.

ANNEKE LUCASSEN

Department of Clinical Genetics, Churchill Hospital, Oxford

\section{Reports from the Holocaust: the making $\stackrel{\triangle}{\circ}$ of an AIDS activist}

Larry Kramer, London, Penguin, 1990, 290 pages, $£ 5.99$

A book such as this emerges from the deepest sense of indignation against a v society that struggles acrimoniously $\overrightarrow{\vec{H}}$ with the acceptance of homosexuality. is Larry Kramer has raised his voice of $\frac{t}{6}$ protest for over a decade, directing his rage at American politicians and 3 members of the medical establishment $\overrightarrow{-}$ who allegedly have been too slow in responding to the AIDS crisis. Kramer uses every expletive available $\stackrel{\text { क }}{+}$ - and then some - in these collected $\vec{\theta}$ speeches and editorials, many 8 published previously in journalisig. protest. A large number of these seething diatribes are directed at American Food and Drug Admint stration (FDA) for moving too conservatively on new interventions into the $\frac{\mathbb{Q}}{2}$ HIV-AIDS continuum. Countless times, Kramer compares what 'they' $\underline{\partial}$ are doing to homosexuals with the Nazi Holocaust. Critically-minded readers will find much to be critical of in Kramer's assertions, but this is protest literature intended to provoke $\widehat{\Phi}$ a response rather than scholarly praise.

While there may have been a tardi- 8 ness in the American political and 3 medical response to AIDS, the facto remains that as of yet this is an epidemic for which medical science $\frac{7}{8}$ offers no cure. It is most interesting to read Kramer's essays as furthering a $\widetilde{N}$ life-conserving tie between sex and love. Kramer rejects the libertarian 0 image of casual sex unrestrained by the absence of love. He offers a romantic notion of love that provides sex with a necessary and essential con- $\frac{\tau}{0}$ text. The stereotype that homosexuals are more promiscuous than heterosexuals is repudiated, although ${ }^{-}$ Kramer allows that promiscuity can $\underset{\mathbb{D}}{\mathbb{D}}$ arise in response to societal scorn.

This is an extremely controversial $\stackrel{\circ}{\circ}$ book, full of rough language and heavy indictments, rooted in the deep pain of the destruction of loved ones. 